\title{
Identifikasi Nematoda Tanah Pada Perkebunan Sawi (Brassica juncea L.) di Kelurahan Landasan Ulin Utara, Banjarbaru, Kalimantan Selatan
}

\author{
Identification of Soil Nematodes in Mustard Plantation (Brassica juncea L.) \\ in Landasan Ulin Utara Village, Banjarbaru, South Kalimantan
}

\author{
Yusinta Oktaviani $^{1 *}$, Abdul Gafur ${ }^{1}$ \\ ${ }^{1}$ Program Studi Biologi, Fakultas Matematika \& Ilmu Pengetahuan Alam, Universitas Lambung Mangkurat, Banjarbaru, 70714, \\ Indonesia \\ Alamat e-mail: yusinta.gbio14@gmail.com
}

\begin{abstract}
Abstrak - Nematoda merupakan cacing mikroskopis yang tergolong dalam biota tanah dengan keanekaragaman spesies yang tinggi. Nematoda memiliki komposisi yang berbeda di berbagai jenis tanah dan daerah. Penelitian ini dilakukan untuk mengetahui keberadaan dan genus nematoda tanah yang terdapat pada tanah perkebunan sawi di Kelurahan Landasan Ulin Utara, Banjarbaru, Kalimantan Selatan. Sampel tanah diambil pada kedalaman 0-20 cm di sekitar rizosfir tanaman sawi yang berlokasi pada lahan perkebunan sayur warga di kawasan Jalan Kurnia dan Jalan Sukamara, Kelurahan Landasan Ulin Utara, Banjarbaru. Ekstraksi untuk memisahkan nematoda dari tanah menggunakan metode Whitehead \& Hemming (1965) dan fiksasi nematoda menggunakan metode Seinhorst (1959). Selanjutnya dilakukan pembuatan preparat permanen nematoda untuk tahap identifikasi dengan pengamatan morfologi \& pengukuran morfometri. Hasil identifikasi menunjukkan bahwa genus nematoda yang ditemukan pada sampel tanah di lokasi penelitian diantaranya adalah Iotonchus, Crustorhabditis, Ironus dan Xiphinema.
\end{abstract}

Kata kunci: identifikasi, nematoda, sawi.

\begin{abstract}
Nematodes are microscopic worms belonging to the soil biota with high species diversity. Nematodes have different compositions in different types of soil and areas. This research is conduct to determine the presence and genus of soil nematodes found in mustard plantations in Landasan Ulin Utara Village, Banjarbaru, South Kalimantan. Soil samples are taken from community vegetable plantations with a depth of 0-20 cm around the mustard plant rhizosphere located in Jalan Kurnia and Jalan Sukamara, Landasan Ulin Utara Village, Banjarbaru. Extraction to separate nematodes from soil using the Whitehead \& Hemming method (1965) and nematode fixation using the Seinhorst method (1959). Furthermore, the permanent nematode preparations were made for the identification stage by morphological observations and morphometric measurements. The identification results showed that the genera of nematodes found in the study site's soil samples were Iotonchus, Crustorhabditis, Ironus, and Xiphinema.
\end{abstract}

Keywords: identification, nematodes, mustard greens.

(C) 2020 Jurnal Jejaring Matematika dan Sains. This work is licensed under a $\underline{\text { CC BY-NC 4.0 }}$

\section{PENDAHULUAN}

Salah satu kota yang menjadi penghasil sayuran di Kalimantan Selatan adalah Kota Banjarbaru, terutama daerah yang terkenal sebagai sentra produksi sayuran di Banjarbaru adalah kelurahan Landasan Ulin Utara, kecamatan Liang Anggang. Sayuran yang dibudidayakan diantaranya yaitu sawi, kangkung, bayam, terong, selada, kacang panjang, kacang tanah, dan daun bawang. Merujuk laporan tahunan Dinas Pertanian dan Tanaman Pangan Hortikultura Provinsi Kalimantan Selatan tahun 2018, rata-rata nilai produktivitas sawi di Kota Banjarbaru dalam 5 tahun terakhir merupakan yang tertinggi kedua se-Kalimantan Selatan, yakni mencapai 6,1 ton/ha. Lebih spesifik, nilai produktivitas sawi di kelurahan Landasan Ulin Utara, Banjarbaru sebagai sentra produksi sayur adalah $6.022,33 \mathrm{ikat} / \mathrm{ha}$ atau 1.500 $\mathrm{kg} / \mathrm{ha}$ [1] Tingginya nilai produktivitas sayur sawi di Kalimantan Selatan, khususnya Kota Banjarbaru, dapat menjadi peluang untuk meningkatkan perekonomian masyarakat petani.

Nematoda adalah cacing tidak bersegmen yang dapat ditemukan di banyak habitat dengan jumlah yang berlimpah di tanah [2] Nematoda sebagian besar mikroskopis dan tidak berwarna dengan ukuran panjang bervariasi dari $0,2 \mathrm{~mm}$ hingga $11,0 \mathrm{~mm}$ dengan diameter $0,01 \mathrm{~mm}$ hingga $0,05 \mathrm{~mm}$ [3]. Peran nematoda dalam penurunan ataupun peningkatan produksi pertanian di Indonesia masih banyak belum disadari oleh para petani. Dampak ekonomi akibat serangan nematoda pada 
tanaman sayur di Indonesia belum dapat diperkirakan pasti, mengingat sampai saat ini data kerusakan yang ada masih bersifat parsial dan hanya berdasarkan hasil-hasil penelitian dalam luasan yang terbatas [4]

Identifikasi spesies nematoda baru atau yang memiliki potensi berbahaya sangat penting dilakukan untuk keberhasilan pertanian dan dapat dijadikan sebagai dasar dalam pengendalian nematoda yang efisien [2]. Penelitian mengenai komposisi nematoda tanah yang terdapat pada perkebunan sawi di Kelurahan Landasan Ulin Utara Banjarbaru, Kalimantan Selatan dilakukan karena jenis nematoda tidak pernah memberikan hasil yang mutlak sama disetiap daerah. Selain itu, informasi mengenai morfologi nematoda yang didapat juga sangat penting untuk penelitian atau studi tingkat lanjut. Penelitian [5] menunjukkan adanya variasi morfologi nematoda rizosfir tanaman dari berbagai daerah di dunia. Berdasarkan hal tersebut, penelitian dilakukan agar didapat data mengenai nematoda tanah pada perkebunan sawi di Kelurahan Landasan Ulin Utara, Banjarbaru, Kalimantan Selatan sebagai tambahan informasi untuk perbandingan dengan daerah lainnya.

\section{METODE PENELITIAN}

Pengambilan sampel tanah berlokasi pada lahan perkebunan sayur warga di kawasan Jalan Kurnia dan Jalan Sukamara, Kelurahan Landasan Ulin Utara, Banjarbaru, Kalimantan Selatan. Penelitian ini dilakukan dengan metode eksplorasi langsung dengan mengambil sampel tanah pada daerah rizosfer tanaman, sedangkan sampel akar diambil dari sawi dengan cara dipotong. Sampel tanah diambil menggunakan sekop kecil, kemudian dimasukkan ke dalam plastik yang selanjutnya diberi label. Pemilihan tanaman sampel dilakukan secara acak dan merupakan tanaman yang akan dipanen, hanya untuk memastikan sistem perakaran sudah mencapai kedalaman dengan kisaran 0-20 cm dimana populasi terbanyak nematoda ditemukan pada lapisan tersebut [6]

\section{A. Bahan \& Alat}

Bahan yang digunakan dalam penelitian ini adalah tanah, air, tisu, kertas label, formalin 4\%, larutan S1 (20 $\mathrm{mL}$ etanol 96\%, $1 \mathrm{~mL}$ gliserol, $79 \mathrm{~mL}$ akuades), larutan S2 (95 mL etanol, $5 \mathrm{~mL}$ gliserol), alkohol absolut, silika gel, parafin, dan spiritus. Alat yang digunakan dalam penelitian ini adalah sekop, kantung plastik, alat tulis, handphone, baki, saringan, saringan mikro ukuran 45 $\mu \mathrm{m}$, alat sederhana penyauk nematoda, botol semprot, cawan petri, tabung reaksi, botol vial, kaca arloji, desikator, oven, pipet tetes, kaca benda, kaca penutup, mikroskop stereo, mikroskop binokuler dengan lensa kamera digital, hot plate, bunsen, dan penjepit kayu.

\section{B. Ekstraksi}

Metode ekstraksi yang digunakan adalah metode Whitehead and Hemming [7] dengan metode ini tanah sampel sebanyak $\pm 200 \mathrm{~g}$ dan potongan akar sawi yang sudah disisihkan ditempatkan pada saringan yang telah dilapisi tisu di bagian atasnya. Kemudian tanah diletakkan secara merata diatas saringan yang telah dilapisi tisu tersebut. Saringan berisi tanah selanjutnya diletakkan di atas baki yang telah diisi air. Saringan diletakkan sedemikian rupa hingga air dapat menggenangi tanah di dalam saringan, namun bagian bawah saringan tidak menyentuh bagian dasar baki. Karena saringan tidak menyentuh bagian dasar baki, maka tersedia cukup ruang bagi nematoda untuk berada di dalam air.

Susunan saringan dan baki ini didiamkan selama 2 hari, selama itu nematoda akan bergerak ke dalam baki dengan mengikuti filum air dan melewati saringan. Setelah 2 hari, nematoda akan berada di dalam baki berisi air endapan hasil saringan. Air ini kemudian disaring kembali menggunakan saringan mikro berukuran $45 \mu \mathrm{m}$ [8] untuk mengurangi jumlah air dan menyeleksi nematoda yang terlalu kecil. Air yang tersisa di dalam saringan mikro mengandung nematoda, kemudian ditampung dalam cawan petri. Cawan petri ini kemudian diamati di bawah mikroskop stereo untuk melihat keberadaan nematoda. Nematoda dapat dilihat dari ciricirinya berdasarkan motilitas (bergerak seperti ular bukan seperti ulat) \& ciri-ciri lain seperti bentuk tubuh membulat dan ada bagian tubuh yang bening antara ujung anterior dengan sistem pencernaan. Nematoda kemudian dipindahkan kedalam botol vial dengan menggunakan alat penyauk sederhana berupa sehelai rambut kuas yang direkatkan pada bilah bambu. Alat ini digunakan untuk mengangkat dan memindahkan nematoda satu persatu.

\section{Fiksasi}

Fiksasi dilakukan dengan menggunakan metode Seinhorst [9] Pada metode ini menggunakan formalin $4 \%$ yang dipanaskan hingga mendidih dan formalin $4 \%$ yang bersuhu ruang. Keduanya dicampurkan kedalam botol vial yang berisi nematoda dengan perbandingan $1: 1$. Nematoda didiamkan dalam larutan formalin selama 2 minggu. Nematoda kemudian dipindahkan kedalam cawan petri yang berisi formalin $4 \%$ dan didiamkan selama tiga hari. Setelah tiga hari, nematoda dimasukkan ke dalam botol kecil berisi larutan Sl $(20 \%$ etanol absolut, $1 \%$ gliserin, dan $79 \%$ air) kemudian botol tersebut diletakkan dalam wadah tertutup berisi alkohol $100 \%$, yang kemudian dimasukkan ke dalam oven dengan suhu $40^{\circ} \mathrm{C}$ selama 24 jam. Setelah 24 jam, larutan S1 diganti dengan larutan S2 (95\% etanol absolut dan $5 \%$ gliserol) untuk kemudian dimasukkan ke dalam desikator berisi silika gel.

\section{Mounting}

Pembuatan preparat permanen menggunakan metode mounting dengan gliserin seperti yang dijelaskan oleh Bezooijen [8]. Cincin parafin dibuat dengan memanaskan mulut tabung reaksi di atas api bunsen, kemudian mulut tabung reaksi yang sudah cukup panas ditempelkan pada padatan parafin yang telah disiapkan 
di dalam cawan petri. Mulut tabung reaksi ditempelkan pada kaca benda sehingga parafin akan membentuk cincin sesuai dengan bentuk mulut tabung. Selanjutnya, setitik gliserin diletakkan di tengah-tengah cincin parafin. Kemudian, satu nematoda yang berada di dalam larutan S2 dipindahkan kedalam titik gliserin, dan diusahakan nematoda diletakkan pada posisi vertikal. Selanjutnya, kaca benda yang telah berisi nematoda ditutup menggunakan kaca penutup dan dipanaskan di atas hot plate hingga parafin mencair. Kaca benda kemudian didinginkan beberapa saat pada suhu ruang hingga parafin mengeras, lalu preparat diamati di bawah mikroskop.

\section{E. Pengamatan Morfologi \& Morfometri}

Nematoda yang diidentifikasi adalah nematoda dewasa yang ditandai dengan adanya sistem reproduksi. Identifikasi dilakukan dengan cara mencocokkan deskripsi morfologi dan pengukuran morfometri dari hasil yang didapat dengan kunci identifikasi pada referensi.

Pengamatan morfologi dilakukan dengan menggunakan buku identifikasi Freshwater Nematodes [10] dan referensi literatur terkait lainnya yang dicantumkan pada daftar pustaka.

\section{HASIL DAN PEMBAHASAN}

Nematoda yang berhasil diidentifikasi dari sampel tanah rizosfer perkebunan sawi (Brassica juncea L.) di Kelurahan Landasan Ulin Utara, Banjarbaru secara keseluruhan berjumlah 17 ekor. Tidak ditemukan nematoda jantan. Nematoda yang diidentifikasi pada sampel tanah dari lokasi penelitian di Jalan Kurnia diantaranya adalah Iotonchus, Crustorhabditis dan Xiphinema. Nematoda yang diidentifikasi pada sampel tanah dari lokasi penelitian di Jalan Sukamara diantaranya adalah Iotonchus, Ironus dan Xiphinema. Rincian mengenai genus dan jumlah nematoda berdasarkan lokasi dapat dilihat pada Tabel 1 .

\section{Iotonchus}

Secara umum tubuh melengkung ke arah ventral terutama di bagian posterior setelah difiksasi (Gambar 1.). Panjang tubuh berkisar antara 1,473-1,550 $\mu \mathrm{m}$. Kutikula halus dan tebal disepanjang tubuh. Bibir sedikit offset dengan lebar antara 27,15-34,52 $\mu \mathrm{m}$ dan tinggi
7,86-11,44 $\mu \mathrm{m}$. Rongga mulut (stoma) cukup besar dengan lebar antara 15,53-20,11 $\mu \mathrm{m}$ dan panjang 31,09$36,12 \mu \mathrm{m}$. Gigi dorsal tajam mengarah ke anterior terletak di bagian posterior rongga mulut, yaitu 6,11$8,40 \mu \mathrm{m}$ dari dasar stoma. Kurang dari seperempat stoma terbungkus oleh jaringan faring. Faring berbentuk tabung panjang dan berotot. Rongga usus cukup lebar dan panjang. Sistem reproduksi monodelfik (satu cabang genital) dengan vulva terletak pada 59\%-67\% panjang tubuh jika diukur dari anterior. Ekor berbentuk filiform (ujung memanjang seperti benang) dengan panjang kurang lebih 8 kali lebar badan anal.

Tabel 1. Data nematoda yang ditemukan dari masing masing lokasi dan dikelompokkan berdasarkan ordo.

\begin{tabular}{|c|c|c|c|}
\hline \multirow{3}{*}{ Ordo } & \multicolumn{2}{|c|}{ Lokasi } & \multirow{3}{*}{ Total } \\
\hline & Jalan Kurnia & $\begin{array}{c}\text { Jalan } \\
\text { Sukamara }\end{array}$ & \\
\hline & Dewasa (q) & $\begin{array}{c}\text { Dewasa } \\
(q)\end{array}$ & \\
\hline \multirow[t]{2}{*}{ Mononchida } & Iotonchus (1) & $\begin{array}{l}\text { Iotonchus } \\
\quad(1)\end{array}$ & \\
\hline & 1 & 1 & 2 \\
\hline \multirow[t]{2}{*}{ Rhabditida } & $\begin{array}{c}\text { Crustorhabditis } \\
\text { (2) }\end{array}$ & - & \\
\hline & 2 & - & 2 \\
\hline \multirow[t]{2}{*}{ Enoplida } & - & Ironus (5) & \\
\hline & - & 5 & 5 \\
\hline \multirow[t]{3}{*}{ Dorylaimida } & Xiphinema (5) & $\begin{array}{l}\text { Xiphinema } \\
\text { (3) }\end{array}$ & \\
\hline & 5 & 3 & 8 \\
\hline & Jumlah Total & & 17 \\
\hline
\end{tabular}

Morfologi spesimen nematoda yang ditemukan ini memiliki kesesuaian dengan deskripsi pada buku Freshwater Nematodes [10] mengenai genus Iotonchus, yang mana menjelaskan bahwa genus ini memiliki ciri panjang tubuh mulai dari 0,8-6,4 $\mathrm{mm}$; stoma yang lebar, terkadang lonjong dan panjangnya berkisar 20-90 $\mu \mathrm{m}$. Gigi dorsal cukup besar, terletak di dekat dasar atau sangat dekat dengan bagian dasar stoma; betina memiliki sistem genital prodelfik atau bisa juga didelfik, dimana nilai V mulai dari 50-80\%; bentuk ekor memiliki kesamaan pada jantan maupun betina, yaitu bervariasi mulai dari sangat pendek dan bulat hingga sangat panjang dan filiform. 


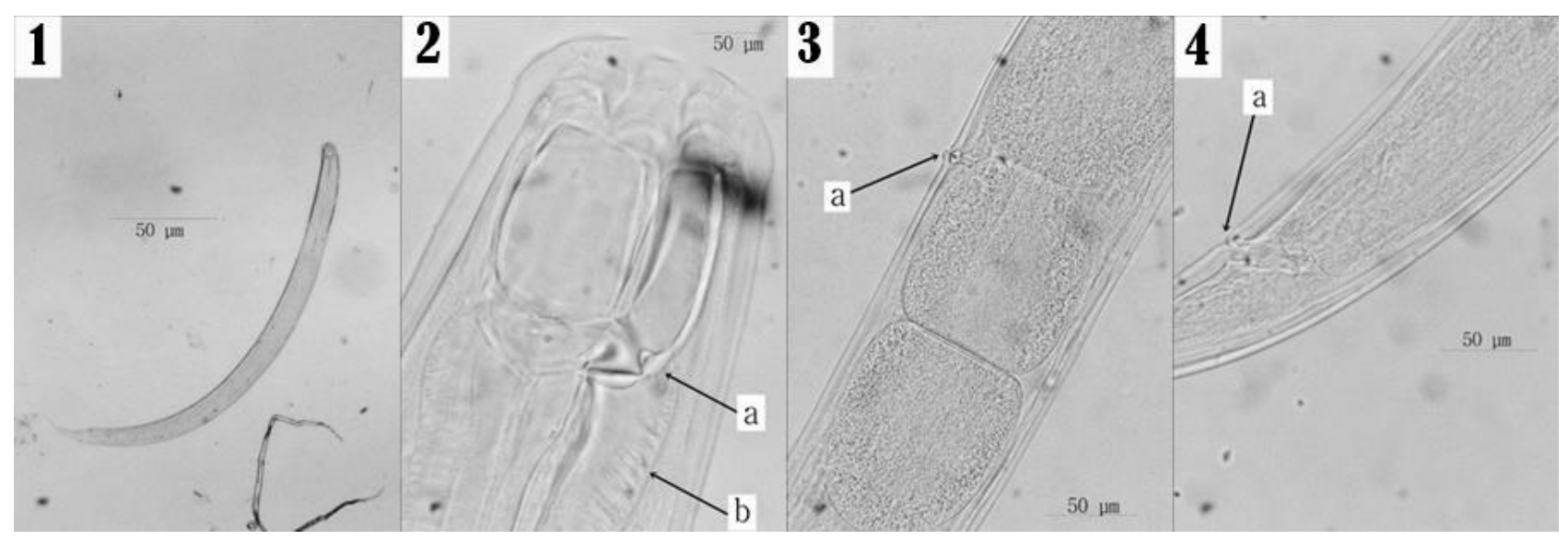

Gambar 1. Iotonchus. 1 : Seluruh tubuh (Perbesaran 40x); 2a : gigi dorsal; 2b : Jaringan faring; 3a : Vulva; 4a : Anus (Perbesaran 400x).

\section{Crustorhabditis}

Bentuk badan simetris bilateral, kutikula beranulasi dengan kisaran panjang tubuh 1368.36-1630.03 $\mu \mathrm{m}$. Stoma cukup panjang, berbentuk seperti pipa (Gambar 2.). Bagian faring terbagi menjadi dua bagian, posterior berbentuk silindris dan bagian posterior mengalami pembengkakan (metacorpus). Letak vulva dekat dengan anus, vulva tidak berkatup. Sistem genital mengarah keatas (prodelfik). Ekor berbentuk tajam pada bagian posterior dengan kisaran panjang 226.6-316.4 $\mu \mathrm{m}$.

Berdasarkan bentuk ujung anterior stoma-bibir, letak vulva dan bentuk ekor, spesimen yang didapatkan memiliki kesesuaian dengan yang dilaporkan [11], [12] menyebutkan bahwa kemiripan Crustorhabditis secara morfologi bertumpang-tindih dengan Mesorhabditis, namun pembedanya adalah ukuran Crustorhabditis sedikit lebih kecil. Spesimen juga memiliki karakteristik yang sesuai dengan deskripsi [13] dimana disebutkan bahwa Crustorhabditis memiliki ukuran tubuh berkisar 0,8-4 mm, kutikula beranulasi melintang, kepala sedikit menonjol (offset), mulut seperti pipa, cheilostom tidak berkutikula, gonad betina prodelfik dan terletak jauh di posterior (berdekatan dengan anus) dan ekor meruncing.

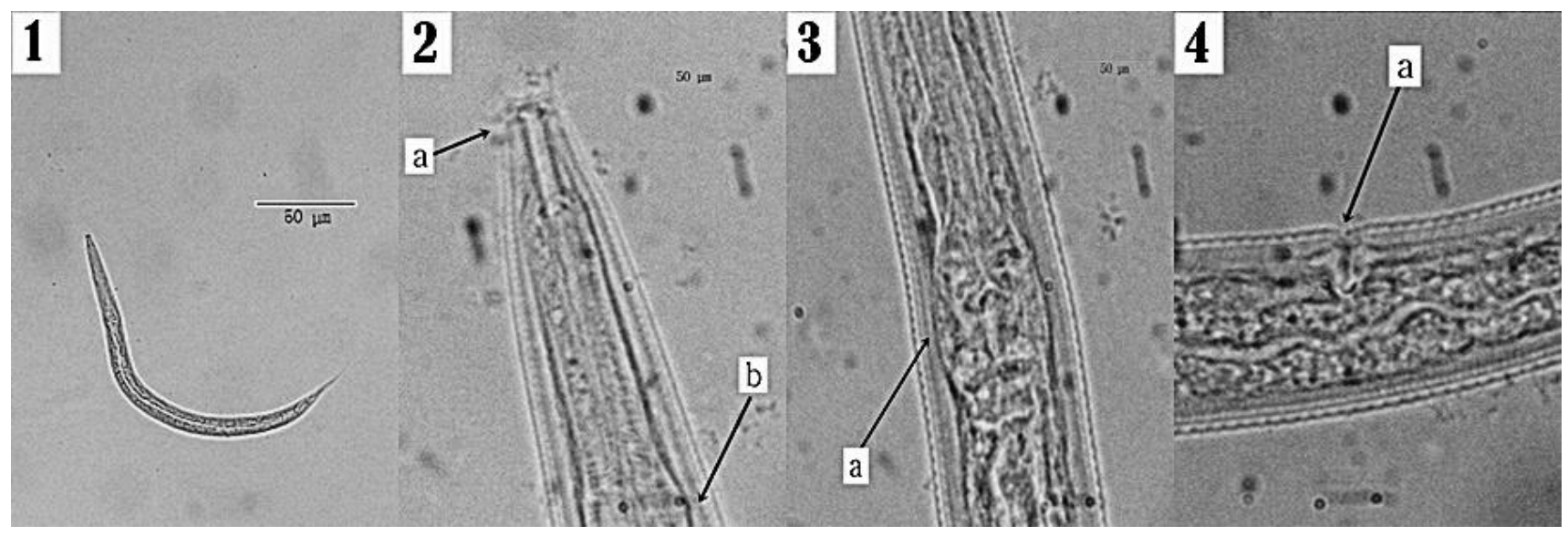

Gambar 2. Crustorhabditis. 1 : Seluruh tubuh (Perbesaran 40x) ; 2a : stoma; $2 \mathrm{~b}:$ procorpus; 3a : metacorpus; 4a : anus (Perbesaran 400x).

\section{Ironus}

Tubuh ramping dengan kutikula halus. Panjang tubuh 1478,87-1624,95 $\mu \mathrm{m}$. Rongga mulut panjang, berbentuk tabung dan sklerotikal. Bentuk menonjol (offset) dengan panjang 6,29-7,09 $\mu \mathrm{m}$, memiliki 3 gigi yang terletak di ujung anterior. Panjang stoma 65,22-71,1 $\mu \mathrm{m}$ dengan lebar 5,33-7,88 $\mu \mathrm{m}$. Faring mengembang secara bertahap ke belakang. Buccal cavity panjang dan berbentuk seperti tabung. Sistem reproduksi betina didelfik dengan posisi vulva $44-51 \%$ dari ujung anterior. Ekor meruncing dengan panjang 284,48-397,52 $\mu \mathrm{m}$.

Secara morfometri spesimen yang ditemukan pada penelitian ini memiliki kesesuaian dengan yang dituliskan oleh [14] yakni memiliki rongga mulut panjang, berbentuk tabung dan memiliki 3 gigi seperti kait yang kuat diujung anterior. Memiliki stoma yang panjang, esofagus seperti silinder dan melebar kebelakang. Sistem reproduksi betina didelfik- 
amfidelfik. Memiliki ekor panjang dan meruncing ke arah ujung.

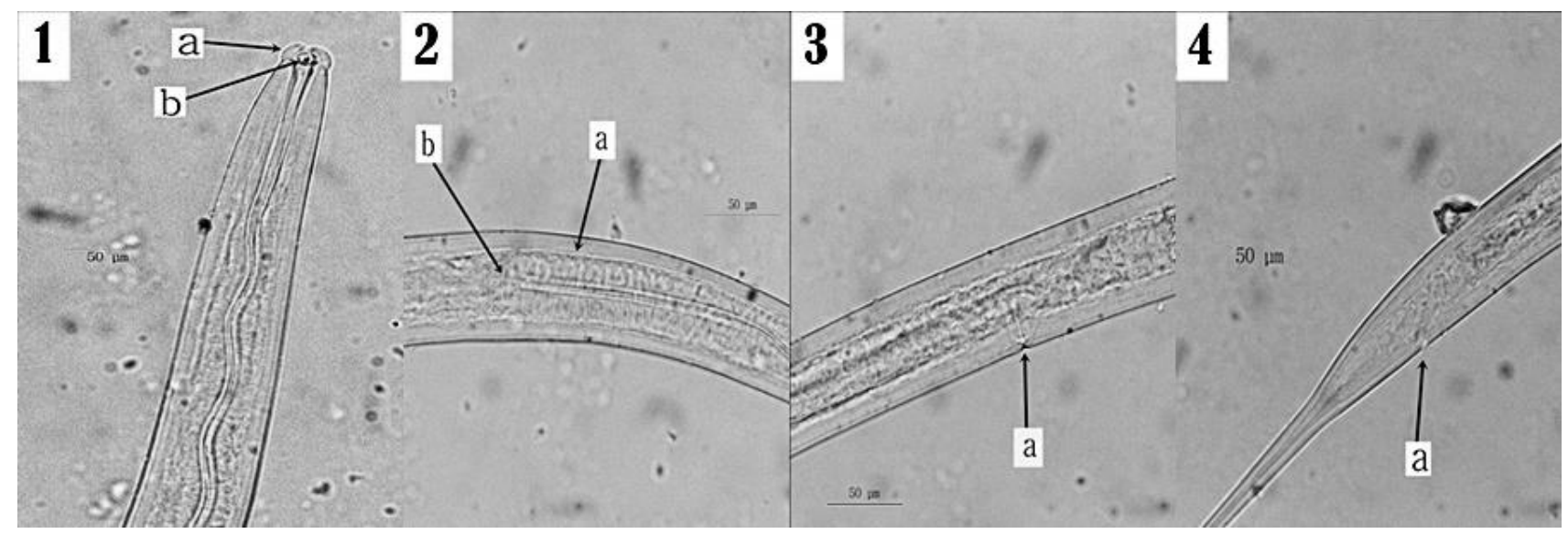

Gambar 3. Ironus. 1a: bibir; 1b: gigi; 2a-b : perbatasan faring dan intestin. 3a : Vulva; 4a : anus (Perbesaran 400x).

\section{Xiphinema}

Tubuh berukuran besar dengan panjang 1680,69$3693,57 \mu \mathrm{m}$. Bagian bibir rata pada bagian ujungnya dengan bagian samping yang membulat. Stilet berbentuk seperti jarum; odontostilet panjang, lurus, meruncing dengan panjang 112,23-168,3 $\mu \mathrm{m}$, cincin penyangga terletak di dekat pangkal odontostilet, panjang odontofor $60,18-91,8 \mu \mathrm{m}$ dan terdapat bagian yang membesar (flange). Sistem reproduksi amfidelfik dengan letak vulva dipertengahan panjang tubuh, nilai $\mathrm{V}: 28-51 \%$. Anus terletak pada bagian posterior tubuh, berekor pendek dengan ujung membulat (conoid).
Umumnya panjang tubuh nematoda genus Xiphinema kurang dari 6 mm [15]. [16] juga menjelaskan kisaran panjang tubuh Xiphinema mulai dari 1,7-3,5 mm. Secara morfometri, spesimen yang ditemukan memiliki kesesuaian dengan yang dituliskan oleh [17]. Batas antara faring dengan intestin terdapat lempeng kardia (cardiac disc) pada bagian tengah posterior faring. Sistem genital betina amfidelfik, ukuran antara cabang anterior dan posterior berkembang sama besar, dan memiliki ekor pendek dan atau membulat pada bagian ujung [18].
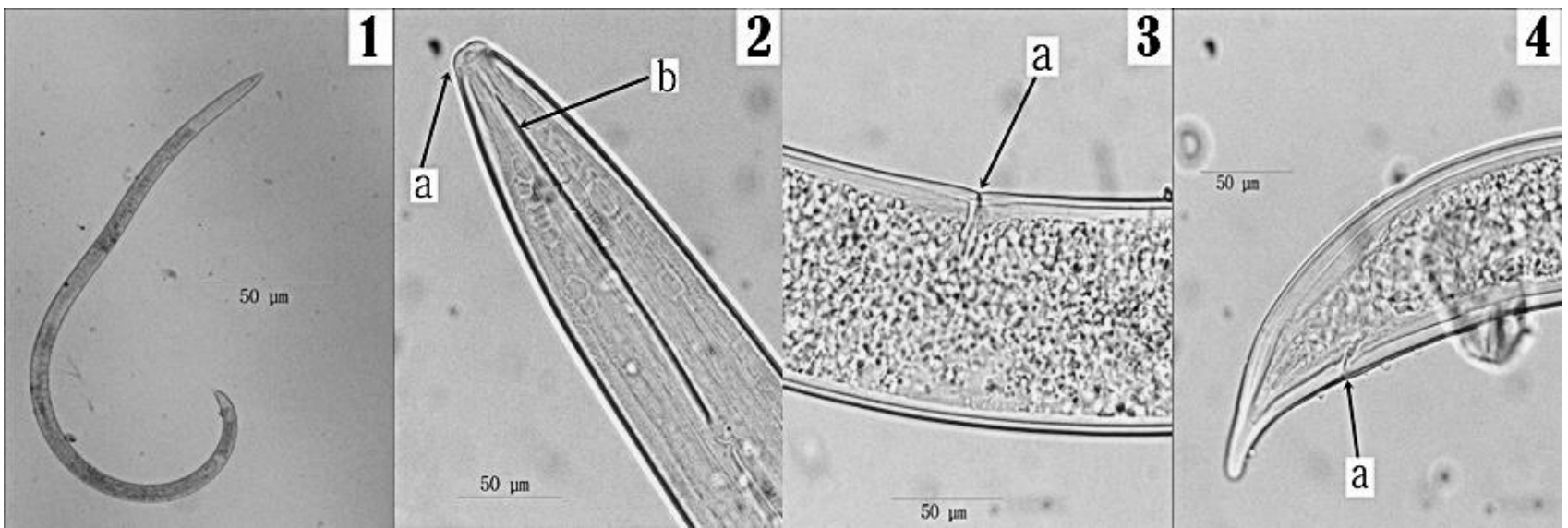

Gambar 4. Xiphinema. 1 : Seluruh tubuh (Perbesaran 40x); 2a : Ujung anterior bibir; 2b : Odontostilet; 3a : Vulva; 4a : Anus (Perbesaran 400x).

Hasil yang didapat dari penelitian nematoda disekitar rizosfir tanaman sawi pada kedua lokasi menunjukkan adanya variasi morfologi dan morfometri yang tidak terlalu menonjol. Nematoda yang ditemukan pada penelitian ini juga sudah pernah dilaporkan sebelumnya di Kalimantan Selatan. Pada penelitian ini nematoda yang berhasil diidentifikasi kesemuanya berjenis kelamin betina. Namun, tidak semua nematoda yang terekstraksi berhasil diidentifikasi. Penyebab beberapa nematoda tidak berhasil diidentifikasi dikarenakan beberapa faktor, yaitu nematoda tersebut masih belum dewasa sehingga belum semua organnya berkembang dengan sempurna, dan atau preparat nematoda tersebut 
mengalami kerusakan sehingga organ kunci identifikasi tidak dapat diamati dengan jelas.

Jika dilihat dari jumlah ordo yang dikoleksi, kelompok nematoda tanah pada rizosfer perkebunan sawi di Kelurahan Landasan Ulin Utara, Banjarbaru cukup beragam. Secara umum, nematoda tanah dapat dikelompokkan berdasarkan kebutuhan makanannya. Empat kelompok pertama disebut nematoda hidup bebas (free-living nematodes), antara lain adalah nematoda pemakan bakteri, nematoda pemakan jamur, nematoda predator dan nematoda omnivora; kemudian kelompok kedua, yaitu nematoda parasit tanaman [19]. Pada penelitian ini, nematoda hidup bebas yang ditemukan jenisnya lebih banyak daripada yang parasit; Iotonchus termasuk nematoda predator karena memiliki rongga mulut yang besar dan dilengkapi gigi untuk memakan nematoda lain, Ironus merupakan predator generalis yang memakan organisme yang lebih kecil, dan Crustorhabditis yang tergolong dalam ordo rhabditida adalah nematoda pemakan bakteri. Jenis nematoda parasit yang ditemukan pada penelitian ini adalah genus Xiphinema. Meskipun ditemukan nematoda parasit, kondisi tanaman sawi pada lokasi pengambilan sampel terlihat sehat. Hal ini kemungkinan dikarenakan jumlah nematoda parasit yang ditemukan berimbang dengan jumlah nematoda kelompok hidup bebas, sehingga efek kerusakan akibat nematoda tidak terlihat signifikan. Menurut [20] nematoda parasit dalam jumlah kecil hanya memberikan efek kecil bagi tanaman inang, namun apabila jumlah nematoda parasit tersebut sangat besar maka dapat menyebabkan kerusakan pada tanaman inang.

\section{KESIMPULAN}

Berdasarkan hasil pengamatan dan proses identifikasi, nematoda yang ditemukan pada sampel tanah perkebunan sawi di Kelurahan Landasan Ulin Utara, Banjarbaru, Kalimantan Selatan, diantaranya adalah Iotonchus, Crustorhabditis, Ironus \& Xiphinema.

\section{REFERENSI}

[1] Suratman. Dinas Pertanian Tan Pang Hortikultura Prov Kalsel, Laporan Tahunan 2018.

[2] Handoo, Z. A. 1998. Plant Parasitic Nematodes. United States Department of Agriculture, USA.

[3] Jonathan, E. I. 2010. Nematology: Fundamentals and Applications. New India Publishing Agency, New Delhi.

[4] Mustika. 2005. Konsepsi dan Strategi Pengendalian Nematoda Parasit Tanaman Perkebunan di Indonesia. Perspektif. 1(1): 20-23.

[5] Uribe, G. E. M. 2008. Biodiversity of Phytoparasitic Nematodes Associated with Musaceae and Fruit Crops in Colombia. Gent Universeteit Belgium.

[6] Rahman, S. A., Zain, S. N. M., Mat, M. Z. B. Sidam, A. K., Othman, R. Y. \& Mohamed Z. (2014). Population distribution of plant parasitic nematodas of banana in Peninsular Malaysia. Sains Malaysiana, 43, 176-177.

[7] Whitehead, A. G. \& J. R. Hemming. 1965. A Comparison of Some Qualitative Methods of Extracting Small Vermiform Nematodes from Soil. Annals of Aplied Biology. 55: 25-38.

[8] Bezooijen, J. Van. 2006. Methodes and Technique For Nematology. Wageningen University, Wageningen.

[9] Seinhorst, J. W. 1959. A Rapid Method for The Transfer of Nematodes from Fixative to Anhydrous Glycerin. Nematologica. 4: 67-69.

[10] Abebe, E., I. Andrássy, \& W. Traunspurger. 2006. Freshwater Nematodes. CABI, Wallingford.

[11] Scholze V. S \& Sudhaus W. 2011. A Pictorial Keyy to Current Genus Groups of Thabdhitidae. Journal Nematode Morpho. 14(2):105-112.

[12] Sudhaus, W. \& Fitch, D.H.A. (2001). Comparative studies on the phylogeny and systematics of the Rhabditidae (Nematoda). Journal of Nematology 33, 1-70

[13] Andràssy, I. 1983. A Taxonomic Review of The Suborder Rhabditina (Nematoda: Secernentia). Editions del Office de la Researche Scientifique et Technique Outramer. Paris. 1240.

[14] Smol \& A. Coomans. 2006. Freshwater Nematodes. CABI, Wallingford.

[15] Bajaj, H. K. \& Jairaipuri, M. S. 1979. A Review of the Genus Xiphinema Cobb, 1913 with Descriptions of Species From India. Records of the Zoological Survey of India. 15 : 255-325.

[16] Swart, A \& P. Quénéherve. 1998. The genus Xiphinema (Nematoda: Longidoridae) in Guyane and Martinique. Fundam. appl. Nematol. 21 (5): 581-604.

[17] Lamberti, F., C.E Taylor \& J.W. Seinhorst. Nematode Vectors of Plant Viruses. Plenum Press, London.

[18] Luc, M. \& A. Dalmasso. 1975. Considerations on the genus Xiphinema Cobb, 1913 (Nematoda: Longidoridae) and a "lattice" for the identification of species. 303-327.

[19] Hoorman, J. J. 2011. The Role of Soil Protozoa and Nematodes. Ohio State University Extension: Columbus.

[20] Tuminem. 2016. Nematoda Puru Akar pada Ubi Jalar (Ipomoea Batatas L.) danPotensi Bakteri Probiotik Tanaman sebagai Agens Biokontrol: Studi Kasus di Papua Barat. Disertasi Sekolah Pascasarjana, Institut Pertanian Bogor, Bogor. 